\title{
Altered Myoelectric Activity in the Experimental Blind Loop Syndrome
}

\author{
P. G. Justus, A. Fernandez, J. L. Martin, C. E. King, P. P. Toskes, \\ and J. R. MAthias, Veterans Administration Medical Center and Department \\ of Medicine, College of Medicine, University of Florida, \\ Gainesville, Florida 32602
}

\begin{abstract}
A B S T R A C T Nutrient malabsorption and diarrhea are characteristic of the blind loop syndrome. Alterations in motility have been implicated as a cause of bacterial overgrowth, but the possibility that altered motility may result from alterations in the flora has not been explored. The purpose of this study was to characterize the myoelectric activity of the small intestine in the blind loop rat model. Eight groups of rats were studied: rats with self-filling blind loops, which develop bacterial overgrowth; rats with selfemptying blind loops, which are surgical controls that do not develop overgrowth; unoperated litter mates; rats with self-filling blind loops and unoperated controls treated with chloramphenicol, $200 \mathrm{mg} / \mathrm{d}$ i.p.; rats with surgically removed self-filling blind loops; operated control rats; and gnotobiotic rats with self-filling blind loops. In the untreated rats with self-filling blind loops, there was altered myoelectric activity characterized by an increased percentage of slow waves occupied by action potentials and by organized activity similar to the migrating action potential complex. Migrating action potential complex activity and percentage of slow waves occupied by action potentials were significantly decreased with chloramphenicol therapy; that decrease correlated with a decrease in aerobes and anaerobes. Migrating action potential complex activity was abolished in rats with surgically removed self-filling blind loops; they also showed a significant decrease in percentage of slow waves occupied by action potentials. Gnotobiotic rats with self-
\end{abstract}

This material was presented at the American Gastroenterological Association meetings in New York, 1981, and Chicago, IL, 1982, and appeared in abstract form in Gastroenterology. 80:1186, and Gastroenterology. 82:1054.

Address reprint requests to Dr. Mathias, Gastroenterology Section (111). Dr. Justus's present address is Portland Veterans Administration Medical Center, Portland, OR 97207.

Received for publication 28 December 1982 and in revised form 18 May 1983. filling blind loops showed no alteration in myoelectric activity. These data indicate: $(a)$ bacterial overgrowth is associated with a significant increase in percentage of slow waves occupied by action potentials and migrating action potential complex activity; (b) chloramphenicol significantly reduced both percentage of slow waves occupied by action potentials and migrating action potential complex activity; and (c) surgical removal of the loop reduced the alterations in motor function. This study suggests that the altered myoelectric activity in this model of bacterial overgrowth was due, in part, to the abnormal bacterial flora and supports the concept that alterations in motility may contribute to the diarrhea that is characteristic of the blind loop syndrome.

\section{INTRODUCTION}

Nutrient malabsorption that is associated with bacterial overgrowth within the small intestine is called the blind loop syndrome (1). The mechanisms underlying these manifestations have been explored in humans with the blind loop syndrome as well as in animal models, such as the blind loop rat (2). Using this model, investigators have documented steatorrhea (3), cobalamin malabsorption (4), decreased brush border enzyme activity (5), impaired sugar and amino acid uptake (5), and mucosal injury (6). To a great extent, these and other abnormalities explain some of the clinical signs and symptoms of the blind loop syndrome.

In addition to specific anatomic alterations, disrupted motility is a prominent etiologic factor in bacterial overgrowth of the small intestine. Vagotomy and hemigastrectomy $(7,8)$, scleroderma (9), diabetic autonomic neuropathy (10), and idiopathic intestinal pseudo-obstruction (11) are diseases characterized by impaired motor function of the intestine and are associated with abnormal proliferation of bacteria within the lumen of the small intestine. A specific mechanism 
by which altered motility may contribute to the development of bacterial overgrowth was suggested by the study of Vantrappen et al. (12). These authors observed the absence of the migrating motor complex $(\mathrm{MMC})^{1}$ in some patients with bacterial overgrowth; however, a specific cause and effect has not been established. The MMC, which is characterized by regular periods of contractions of the small intestine, may have its origin in the distal esophagus, stomach, or duodenum, and it migrates to the terminal ileum every 90-110 min in humans (13). Although the physiologic function of the MMC has not yet been conclusively determined, Code and Schlegel (14) have suggested that the MMC may act as a clearing mechanism in the fasted state. An absence of the MMC in some of the patients described by Vantrappen et al. (12) may have contributed to the overgrowth of bacteria in the small intestine. Thus, the alteration in motility of the small intestine, in the absence of anatomic defects, can cause the blind loop syndrome. However, the effects of the overgrowth flora on the motor function of the small intestine have not been explored.

In a series of recent animal studies, we have shown that specific pathogenic bacteria or their enterotoxins alter the motor function of the small intestine (15-19). Myoelectric recording techniques were used for all studies. The specific alterations in myoelectric activity that were observed correlated with the clinical characteristics of the infectious agent studied. Noninvasive bacteria or their enterotoxins, which are associated clinically with profuse diarrhea and minimal abdominal pain, induced a propulsive motor pattern called the migrating action potential complex (MAPC) (15, 16). Invasive bacteria or their cytotoxins, which produced illness characterized by moderate to severe pain and less diarrheal output, induced a less propulsive motor complex called repetitive bursts of action potentials (RBAP) (17-19).

Could proliferation of a diverse bacterial flora such as that which occurs in the blind loop syndrome be associated with alterations in motility of the small intestine? The aims of this study were: $(a)$ to characterize the myoelectric activity of the small intestine in the blind loop rat model, which uniformly develops bacterial overgrowth; $(b)$ to examine the effects of a specific antibiotic, chloramphenicol, on any observed alteration in motor function in the rat model; and $(c)$ to assess whether any altered myoelectric activity

\footnotetext{
${ }^{1}$ Abbreviations used in this paper: MAPC, migrating action potential; MMC, migrating motor complex; RBAP, repetitive bursts of action potentials; SEBL, self-emptying blind loop; SFBL, self-filling blind loop; SW-AP, slow waves occupied by action potential(s).
}

could be eliminated by surgical removal of the blind loop.

\section{METHODS}

Animal preparation. Male Wistar rats (Charles River Breeding Laboratories, Inc., Wilmington, MA) weighing between 150 and $250 \mathrm{~g}$ were housed two to a cage and fed standard laboratory rat food and water. After an overnight fast, the animals were anesthetized with sodium pentobarbital (40 mg/kg i.p.), and self-filling blind loop (SFBL) or self-emptying blind loop (SEBL) preparations were constructed in a manner previously described (2). A $10-\mathrm{cm}$ blind loop was constructed and connected to the remaining jejunum of an anastamotic point $10 \mathrm{~cm}$ from the ligament of Treitz; this created a blind loop that was either self-filling or self-emptying (Fig. 1). In the SFBL rats, aboral movement of intestinal contents tended to keep the blind loop filled, and thus promoted stagnation. Bacterial overgrowth invariably ensues within $3 \mathrm{~d}$ of creating the SFBL (20). In contrast, the blind loops of the SEBL rats were constructed so that intraluminal contents were cleared from the blind loop segment into the adjacent jejunum, and thus stagnation and resultant overgrowth of bacteria were avoided.

Three experimental groups comprising eight different models were prepared. The first experimental group consisted of SFBL rats $(n=7)$, SEBL rats $(n=6)$, and unoperated litter mates $(n=6)$. The second experimental group consisted of SFBL rats $(n=8)$ and unoperated control rats $(n=8)$ that received chloramphenicol, $200 \mathrm{mg} / \mathrm{d}$ i.p. Chloramphenicol has been shown to suppress both aerobic and anaerobic bacterial counts in this model (5). All animals were allowed to recover and were stabilized for $2 \mathrm{wk}$ until the myoelectric studies were performed. The third experimental group consisted of SFBL rats in which the blind loop was surgically excised and an end-to-end anastomosis was constructed. Myoelectric recordings were obtained at $2 \mathrm{~d}$ ( $n$ $=6), 14 \mathrm{~d}(n=6)$, and $21 \mathrm{~d}(n=6)$ after loops were removed. Control preparations, in which the $10-\mathrm{cm}$ segment of jejunum that corresponded to the blind loop was removed, were also studied at comparable time periods. Finally, SFBL rats prepared under gnotobiotic conditions $(n=2)$ were also studied.

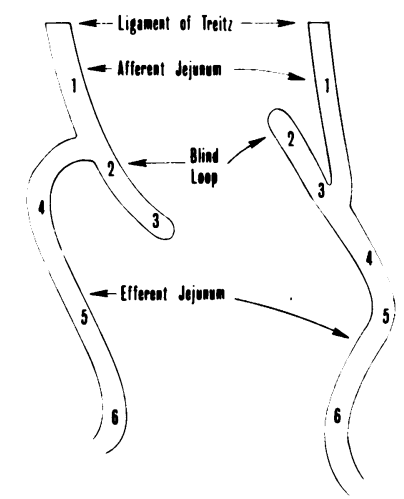

FIGURE 1 SFBL (left) and SEBL (right) rat preparations are schematically illustrated. Both blind loops were constructed $10 \mathrm{~cm}$ from the ligament of Treitz. Electrode placement is also shown and corresponds to the following sites: 1, afferent jejunum; 2 and 3 , the blind loop (SFBL or SEBL); 4, 5, and 6 , efferent jejunum. 
Myoelectric studies. The animals were fasted overnight and then anesthetized with sodium pentobarbital $(40 \mathrm{mg} / \mathrm{kg}$ i.p.). Through a midline abdominal incision, the afferent jejunum, the blind loop, and the efferent jejunum were identified. Monopolar silver-silver chloride electrodes were sutured to the serosa of the afferent jejunum at $5 \mathrm{~cm}$ from the anastomosis, at two sites that were $5 \mathrm{~cm}$ apart on the blind loop, and on the efferent jejunum at three sites that were 5 $\mathrm{cm}$ apart and that began at $5 \mathrm{~cm}$ from the blind loop anastamosis (Fig. 1). The electrodes were placed at corresponding sites of $5,12.5,17.5,25,30$, and $35 \mathrm{~cm}$ from the ligament of Treitz in the unoperated control rats and the control rats, from which a $10-\mathrm{cm}$ loop of jejunum that corresponded to the area of the blind loop was removed. In the rats with extirpated loops, electrodes $(1,4-6)$ were placed at corresponding sites above and below the end-to-end anastamosis (Fig. 1). The electrodes were connected to a physiologic recorder via 9806 AC couplers (both from Beckman Instruments, Inc., Fullerton, CA). An indifferent electrode was placed into the subcutaneous tissue of a hind limb. Body temperature was monitored by an intraperitoneal thermometer and maintained by a heating pad (Aquamatic K-Pad, Gorman-Rupp Industries Div., Belleville, $\mathrm{OH}$ ). Myoelectric recordings were made with a sensitivity of $0.02 \mathrm{mV} / \mathrm{cm}$, a time constant of $1 \mathrm{~s}$, a high-frequency filter of $30 \mathrm{~Hz}$, and a paper speed of $2.5 \mathrm{~mm} / \mathrm{s}$. The recording period for each preparation was $2 \mathrm{~h}$.

Statistical analyses. All myoelectric recordings were analyzed for slow wave frequency, altered myoelectric complex activity (MAPC), and percentage of slow waves occupied by action potentials $(\mathrm{SW}-\mathrm{AP})>1 \mathrm{~s}$ in duration.

Statistical analyses performed included $F$ tests for analysis of variance and the $t$ test for comparison of means (21). The experiments involving groups of antibiotic treated and untreated blind loop and control rats were analyzed using nonparametric statistical tests (21). Paired means were examined using the Wilcoxon rank sum test, and analysis of variance was performed using the Kruskal-Wallis test (21).

Bacteriologic studies. Animals from each test group were killed by overdose of sodium pentobarbital. Segments of the afferent jejunum, blind loop, and efferent jejunum or corresponding sites in the operated and the unoperated control rats were tied off, excised, and placed in anaerobic transport jars. Aerobic and anaerobic cultures were performed as previously described (22).

\section{RESULTS}

Myoelectric recordings from SEBL and operated or unoperated control rats consisted of slow wave activity with occasional single action potentials or short bursts of action potential activity of $<1 \mathrm{~s}$ (Fig. 2 A). Mean slow wave frequencies for the SEBL rats were $35 \pm 0.8$, $30 \pm 0.7$, and $29 \pm 0.4$ cycles $/ \mathrm{min}$ for the afferent jejunum, blind loop, and efferent jejunal segments, respectively. The slow wave frequencies for SFBL rats were $38 \pm 2.2,32.6 \pm 1.7$, and $33 \pm 0.9$ cycles $/ \mathrm{min}$ in the afferent jejunum, blind loop, and efferent jejunum, respectively; these values were not significantly different from the slow wave frequency in the SEBL rats.

The number of slow waves containing action potential activity was increased in the SFBL compared with SEBL rats or with operated or unoperated control rats.
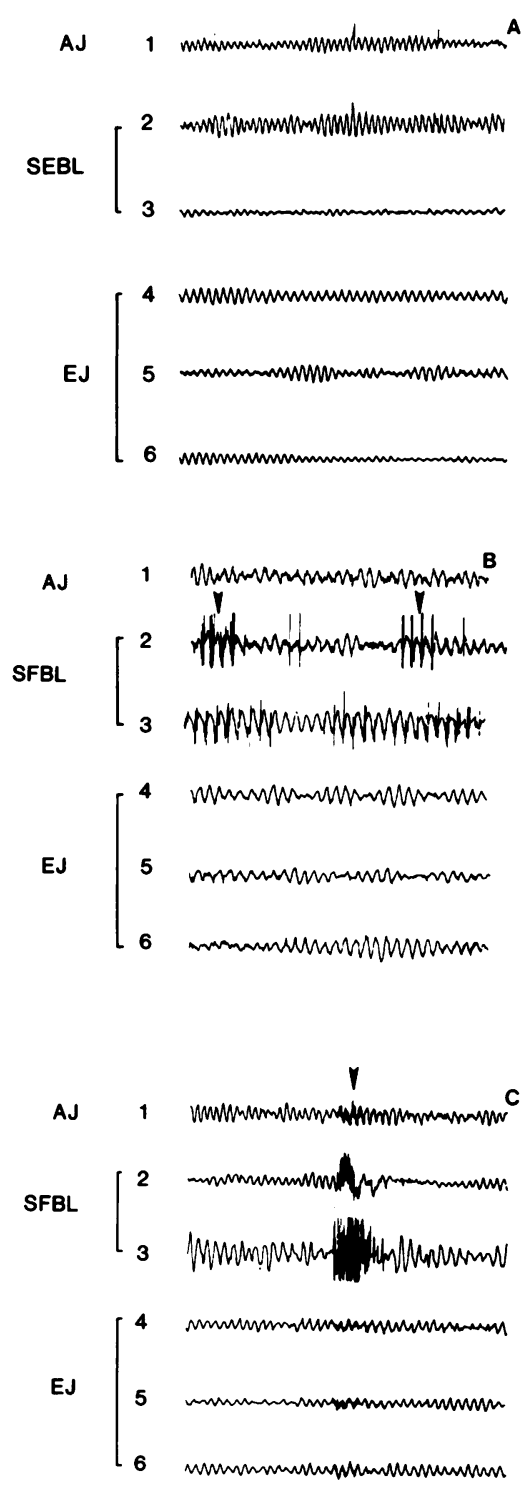

FIGURE 2 (A) Representative myoelectric tracing taken from operated or unoperated control or SEBL rats. Electrode placement (Nos. 1-6) is illustrated schematically on the left and corresponds to electrode sites illustrated in Fig. 1. AJ, afferent jejunum; $E J$, efferent jejunum. (B) Representative myoelectric tracing taken from SFBL rats that illustrate examples of the percentage of SW-AP bursts longer than $1 \mathrm{~s}$ in duration (arrows). (C) Representative myoelectric tracing taken from SFBL rats that illustrate an example of MAPC (arrow)

This increased activity, which was observed within 24 min after initiating the recording, could be categorized into two distinct patterns. The first pattern consisted of slow waves with bursts of action potential activity $>1 \mathrm{~s}$ in duration (percentage of SW-AP). These bursts of action potentials usually occurred on one slow 
wave cycle, but some lasted over two to three slow wave cycles (Fig. 2 B). The second pattern of increased action potential activity was more prolonged on each recording site (2-12 s) and migrated over distal electrode recording sites (Fig. $2 \mathrm{C}$ ). This organized activity was similar to the MAPC activity caused by cholera toxin (15). The propagation velocity of these MAPC was faster than the MAPC reported for cholera toxin and often occurred simultaneously on all recording sites.

Fig. 3 shows the percentage of SW-AP in the afferent jejunum in SFBL rats $(6.5 \pm 2.7 \% \mathrm{SW}-\mathrm{AP}$, mean \pm SEM) compared with SEBL rats $(0.009 \pm 0.009 \%)$ or with operated or unoperated control rats $(0.024 \pm 0.024 \% ; P<0.05)$. The blind loop segment showed $7.3 \pm 1.4 \% \mathrm{SW}$-AP in SFBL rats compared with 0 for the SEBL rats $(P<0.01)$. In the efferent jejunum, there were $4.6 \pm 1.3 \% \mathrm{SW}-\mathrm{AP}$ in the SFBL rats, $0.046 \% \pm 0.026 \%$ for SEBL rats, and 0 for unoperated controls $(P<0.01)$.

The SFBL rats treated with chloramphenicol (Fig. 3) showed a significantly lower percentage of SW-AP in the blind loop and efferent jejunum than did untreated control SFBL rats $(7.3 \pm 1.4 \%$ vs. $3.7 \pm 0.8 \%, P$ $<0.05$; and $4.6 \pm 1.3 \%$ vs. $1.5 \pm 0.7 \%, P<0.05$, respectively). Chloramphenicol-treated unoperated control rats did not differ significantly from nontreated unoperated control rats. Chloramphenicol was not associated with any significant change in slow wave frequency among the groups.

The frequency of MAPC was assessed for each group (Fig. 4). There were $12.8 \pm 4.3 \mathrm{MAPC} / \mathrm{h}$ in the SFBL rats. No MAPC activity was seen in the SEBL rats or in the operated or unoperated controls. Chloramphenicol treatment of SFBL rats produced a significant reduction in MAPC activity $(2.0 \pm 1.1 \mathrm{MAPC} / \mathrm{h}, P$ $<0.01$ ).
All activity (percentage of SW-AP and MAPC) was significantly reduced at 2,14 , and $21 \mathrm{~d}$ after removal of the blind loop. By the second day, MAPC activity was markedly reduced $(1.63 \pm 0.42 \mathrm{MAPC} / \mathrm{h}, P<0.01$; Fig. 5) and percentage of SW-AP was significantly reduced at $2 \mathrm{~d}$ after surgical removal of the loop $(P$ $<0.01$ ) and remained at these values at $21 \mathrm{~d}$ after removal (Fig. 6). Gnotobiotic preparations demonstrated no MAPC activity and only minimal activity in the efferent segment.

The results of the quantitative aerobic and anaerobic bacterial cultures for the various experimental groups are shown in Table I. The bacterial flora in the blind loop rats was similar qualitatively and quantitatively in the three jejunal segments (afferent jejunum, blind loop, and efferent jejunum). Unoperated or operated control rats had substantial flora of the small intestine; the aerobic flora consisted primarily of gram-positive organisms. Bacteroides was not found in control rats. The total counts of bacteria in the SFBL rats were characteristically increased by 2-3 logs. Among the aerobic bacteria, gram-negative rods consistently predominated, especially Escherichia coli and Proteus. The gram-positive anaerobic microflora were greatly increased compared with the corresponding control flora; however, gram-negative rods, primarily Bacteroides, were the most prevalent group of organisms. Thus, the largest increases were in the total gram-negative flora and in the total anaerobic flora. These alterations in bacterial flora were associated with an increase in both percentage of SW-AP and in MAPC activity. Rats with the SEBL did not develop bacterial overgrowth and myoelectric activity was similar to that in control rats. Choramphenicol treatment of the SFBL rats substantially decreased both aerobes and anaerobes, except for Pseudomonas, which was present in numbers higher than those in control rats or in

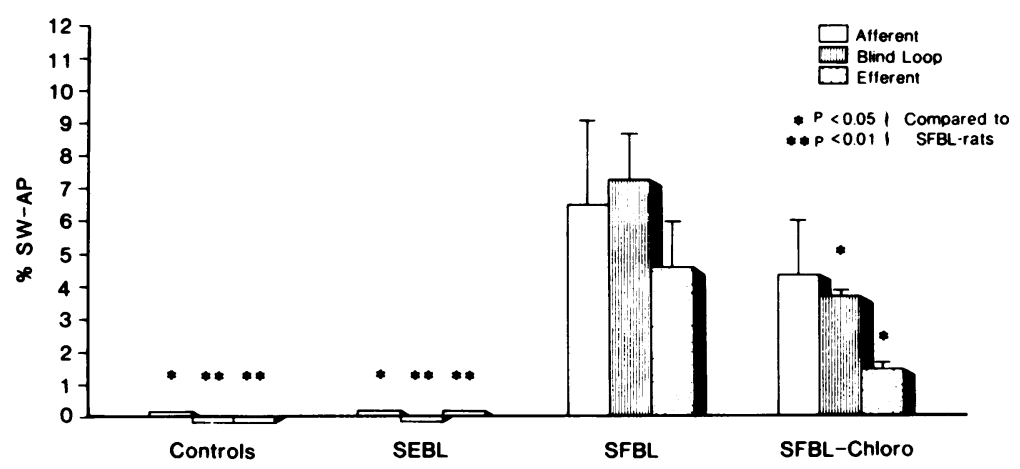

FIgure 3 The percentage of SW-AP in control rats, SEBL rats, SFBL rats, and SFBL rats treated with chloramphenicol. The percentage of SW-AP was significantly decreased in the blind loop segment and the efferent segment $(P<0.05)$ after treatment with chloramphenicol. Minimal percentage of SW-AP was seen in controls or the SEBL rats. Chloro, chloramphenicol. 


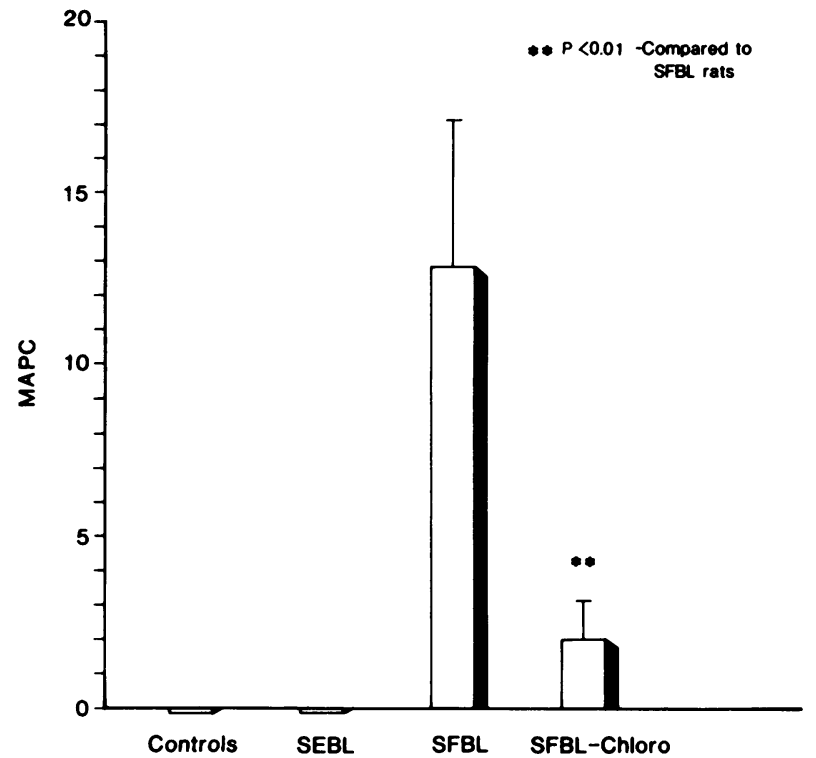

Figure 4 The number of MAPC per hour in control rats, SEBL rats, SFBL rats, and SFBL rats treated with chloramphenicol. The number of MAPC significantly decreased after treatment with chloramphenicol $(P<0.01)$. Chloro, chloramphenicol.

untreated SFBL rats. Chloramphenicol had a profound effect on the anaerobic flora; it completely eliminated all the anaerobes except Bacteroides and Veillonella, which were decreased by 5 and 3 logs, respectively. This effect on the flora was associated with a reduction in both the percentage of SW-AP and MAPC activity.
Chloramphenicol treatment of control rats (data not shown) not only resulted in a marked decrease in both the normal aerobic and anaerobic flora, but also resulted in an increase in Pseudomonas by some 4 logs over untreated control rats and an increase in Bacteroides from zero in untreated control rats to $3.6 \pm 0.1$ logs.

\section{DISCUSSION}

Many of the known pathophysiologic derangements encountered in the blind loop syndrome, such as malabsorption of fat, carbohydrates, water, and electrolytes, and bile salt deconjugation could contribute to the diarrhea found in patients with this syndrome (1). Prior myoelectric studies with specific bacteria or their enterotoxins $(15,16)$ and invasive bacteria or their cytotoxins (17-19) demonstrated alterations in the motility of the small intestine. This study suggests that the overgrowth of bacteria within the lumen of the small intestine, like the specific bacteria studied previously, altered the motor function of the small intestine in a similar manner. The myoelectric alterations were characterized by increased action potential activity that consisted of either short random bursts (percentage of SW-AP) or prolonged organized activity (MAPC).

The increase in percentage of SW-AP resembled the myoelectric pattern described secondary to invasive bacteria or their cytotoxins, i.e., RBAP (17-19). In addition, the organized action potential activity observed in SFBL rats is similar to the MAPC caused by noninvasive bacteria, such as Vibrio cholerae (15) or tox-

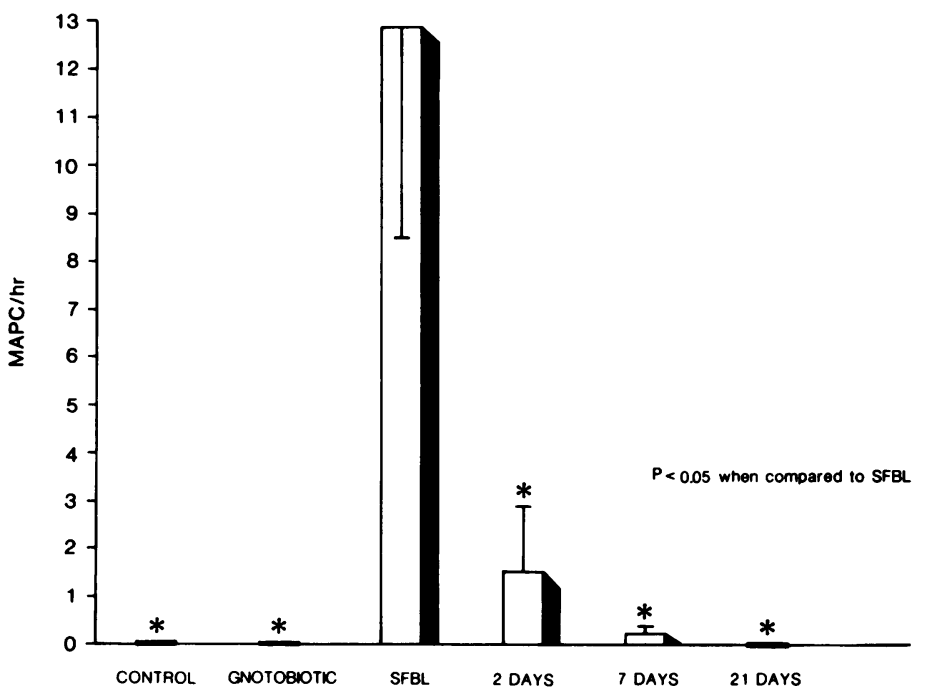

FIgure 5 The number of MAPC per hour in control rats, gnotobiotic rats, and SFBL rats, and at 2,7 , and $21 \mathrm{~d}$ after the loops were surgically removed. Significant reduction in MAPC was observed at 2 and $7 \mathrm{~d}(P<0.05)$. No MAPC were seen at $21 \mathrm{~d}$. 


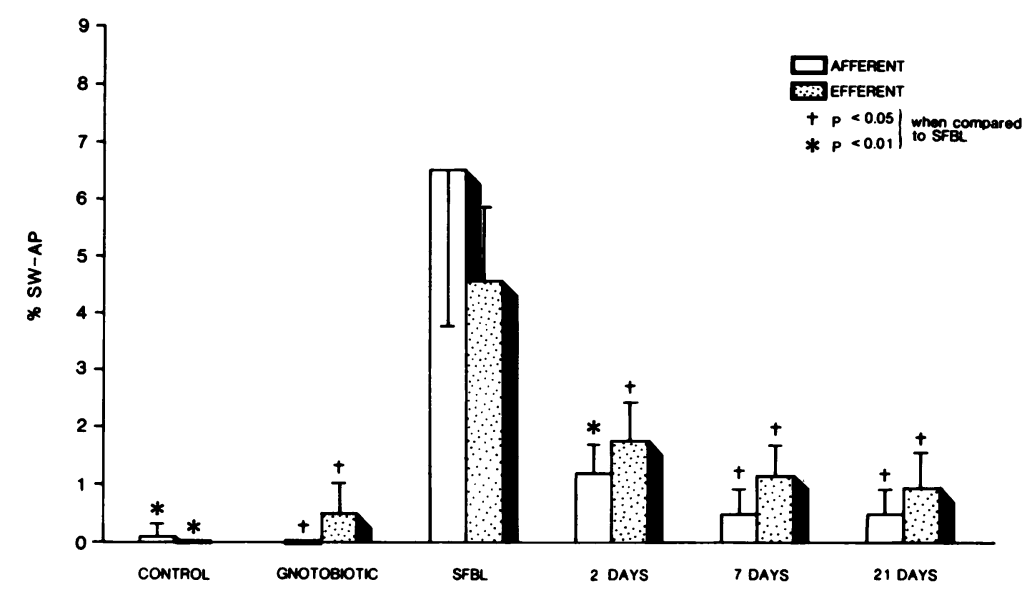

FIGURE 6 The percentage of SW-AP in control rats, gnotobiotic rats, SFBL rats, and SFBL rats after the loops were extirpated at 2,7 , and $21 \mathrm{~d}$. There was a significant reduction in percentage of SW-AP at 2,7 , and $21 \mathrm{~d}(P<0.05)$. Complete cessation of percentage of SWAP was not observed up to $21 \mathrm{~d}$. Minimal percentage of SW-AP was seen in control or gnotobiotic rats.

igenic $E$. coli (16). The MAPC activity observed in the blind loop syndrome had a propagation velocity that was much faster than that which was observed to occur with other specific organisms and it often appeared to occur simultaneously on all leads. The MAPC previously observed after specific bacterial pathogens was clinically associated with marked diarrheal output.
The MAPC has been shown to enhance the aboral movement of luminal contents (23).

The design of the study does not allow us to report which part of the overgrowth flora is related to the alterations in motor activity because chloramphenicol suppressed both aerobic and anaerobic growth. Indeed, the marked quantitative change may not be as

TABLE I

Bacterial Flora of Jejunal Segments in Control and Blind Loop Rats

\begin{tabular}{|c|c|c|c|c|c|c|c|}
\hline & \multirow[b]{2}{*}{$\begin{array}{c}\text { Control } \\
\text { untreated }(n=4) \\
\text { jejunum }\end{array}$} & \multicolumn{2}{|c|}{$\begin{array}{c}\text { SFBL } \\
\text { untreated }(n=5)\end{array}$} & \multicolumn{2}{|c|}{$\begin{array}{c}\text { SEBL } \\
\text { untreated }(n=4)\end{array}$} & \multicolumn{2}{|c|}{$\begin{array}{l}\text { SFBL chloramphenicol } \\
\text { treated }(n=6)\end{array}$} \\
\hline & & Blind loop & $\begin{array}{l}\text { Efferent } \\
\text { jejunum }\end{array}$ & Blind loop & $\begin{array}{l}\text { Efferent } \\
\text { jejunum }\end{array}$ & Blind loop & $\begin{array}{l}\text { Efferent } \\
\text { jejunum }\end{array}$ \\
\hline \multicolumn{8}{|l|}{ Aerobes } \\
\hline E. coli & $8.6 \pm 0.1$ & $11.4 \pm 0.6$ & $11.3 \pm 0.3$ & $9.2 \pm 0.1$ & $5.5 \pm 0.1$ & 0 & 0 \\
\hline Proteus & $6.9 \pm 0.1$ & $10.5 \pm 0.2$ & $9.5 \pm 0.3$ & $3.5 \pm 0.5$ & $6.2 \pm 0.6$ & $3.5 \pm 0.1$ & $3.9 \pm 0.4$ \\
\hline Pseudomonas & $5.2 \pm 0.8$ & $\mathbf{0}$ & $\mathbf{0}$ & $5.4 \pm 0.4$ & $5.9 \pm 0.5$ & $8.1 \pm 0.4$ & $7.8 \pm 0.1$ \\
\hline Streptococci & $6.2 \pm 0.6$ & $9.3 \pm 0.1$ & $9.3 \pm 0.6$ & $6.8 \pm 0.5$ & $7.4 \pm 0.5$ & $7.2 \pm 0.1$ & $6.9 \pm 0.2$ \\
\hline Staphylococci & $6.1 \pm 0.9$ & $6.8 \pm 0.1$ & $6.4 \pm 0.2$ & $4.1 \pm 0.1$ & $5.2 \pm 0.1$ & $3.5 \pm 0.2$ & $3.3 \pm 0.7$ \\
\hline Total & $8.7 \pm 0.3$ & $11.7 \pm 0.2$ & $11.4 \pm 0.4$ & $5.5 \pm 0.1$ & $7.2 \pm 0.3$ & $8.1 \pm 0.4$ & $7.9 \pm 0.1$ \\
\hline \multicolumn{8}{|l|}{ Anaerobes } \\
\hline Bacteroides & 0 & $11.2 \pm 0.1$ & $10.4 \pm 0.1$ & 0 & 0 & $6.5 \pm 0.1$ & $6.3 \pm 0.1$ \\
\hline Fusobacteria & $8.9 \pm 0.2$ & $9.9 \pm 0.1$ & $8.2 \pm 0.3$ & $9.2 \pm 0.1$ & $8.4 \pm 0.2$ & 0 & 0 \\
\hline Clostridia & 0 & $9.8 \pm 0.5$ & $10.1 \pm 0.7$ & $4.1 \pm 0.1$ & $3.9 \pm 0.1$ & 0 & 0 \\
\hline Veillonella & 0 & $8.4 \pm 0.1$ & $8.2 \pm 0.6$ & $5.3 \pm 0.5$ & $4.8 \pm 0.2$ & $5.9 \pm 0.4$ & $5.8 \pm 0.4$ \\
\hline Other gram-negative rods & 0 & $6.4 \pm 0.2$ & $5.5 \pm 0.4$ & $3.2 \pm 0.1$ & $3.6 \pm 0.1$ & 0 & 0 \\
\hline Gram-positive cocci & $5.9 \pm 0.2$ & 0 & 0 & $3.8 \pm 0.1$ & $3.8 \pm 0.3$ & 0 & 0 \\
\hline Total & $8.9 \pm 0.5$ & $11.3 \pm 0.3$ & $10.7 \pm 0.3$ & $5.5 \pm 0.4$ & $5.2 \pm 0.1$ & $6.6 \pm 0.2$ & $6.4 \pm 0.4$ \\
\hline
\end{tabular}

0 indicates that the organism was not detected in culture. Data indicate No. of bacteria per gram of jejunal content \pm 1 SEM, log 10. 
important as alterations in the metabolic properties of the bacteria, but the evidence from this study suggests that the altered motor activity resulted from the abnormal flora. The alterations in motor function may be secondary to increases in certain bacteria, in enterotoxins produced by the bacteria, or in metabolic by-products of the bacteria per se. However, significant myoelectric changes were observed only in rats with bacterial overgrowth (SFBL rats). The SFBL rats treated with chloramphenicol had a significant suppression of the bacterial flora and had a significantly lower percentage of SW-AP and less MAPC activity than did untreated SFBL rats. These observations would suggest that members of the chloramphenicol-sensitive flora were at least partially responsible for the altered myoelectric activity. Furthermore, no alterations in myoelectric activity were observed in the SFBL rats prepared under gnotobiotic conditions.

The possibility exists that intestinal distention may have caused some of the motor disturbances. A recent study by Summers et al. (24) showed that in acute canine intestinal obstruction, action potential activity increases in the obstructed segment and decreases in the distal unobstructed segment if the obstruction is applied when the animals have been fed; during the fasted state, no changes from base-line myoelectric activity are noted. Since $(a)$ the animals in this study were fasted and $(b)$ the enhanced spiking activity occurred in the adjacent, unobstructed jejunal segments as well, we doubt whether the changes in myoelectric activity resulted from acute distention. Furthermore, the gnotobiotic SFBL rats showed no difference in activity compared with that in operated or unoperated control rats. Lastly, antibiotic therapy, although it did not alter either the basic anatomy of the model or appreciably affect the amount of material observed in the blind loop segment itself, was associated with significant suppression of the altered motor activity.

Chloramphenicol could have suppressed the increased action potential activity through mechanisms independent of its effects on the bacterial flora; however, in the control rats that were administered chloramphenicol, the percentage of SW-AP was slightly increased in the efferent jejunum compared with that in untreated controls.

Dramatic changes in the altered myoelectric activity occurred at 2,14 , and $21 \mathrm{~d}$ after removal of the blind loop. The most obvious change was the immediate decrease of the MAPC activity that is characteristic of heat-labile enterotoxins. The MAPC activity decreased to $2.1 \pm 0.4 \mathrm{MAPC} / \mathrm{h}$ at $2 \mathrm{~d}$ and was absent at 14 and $21 \mathrm{~d}$. The percentage of SW-AP also decreased but remained significantly elevated at all three time periods. Since the percentage of SW-AP is similar to
RBAP activity, which is characteristic of invasive bacteria or cytotoxins causing enterocyte injury, we suggest that the persistence of this activity after the loop was extirpated is a reflection of persistent gut damage that often requires weeks to months for complete recovery and reversal of the malabsorption defects (1).

In summary, this study indicates that increased action potential activity is associated with abnormal flora found in the blind loop rat model of the blind loop syndrome. Therefore, altered motility may not only result in the overgrowth, but also may contribute to the blind loop syndrome by increased random action potential activity and the presence of the MAPC.

\section{ACKNOWLEDGMENTS}

We wish to acknowledge and thank Mrs. Frances Tucker and Ms. Anne Barry for typing the manuscript, Mrs. Alice Cullu for her editorial assistance, and Ms. Debora Duncan and Ms. Loren Snook for their technical assistance in preparation of the blind loop rats. Also, we wish to thank Dr. Theodore W. Burns, Oschner Clinic, New Orleans, LA, for the opportunity to study the gnotobiotic SFBL rats.

This work was supported by the Medical Research Service of the Veterans Administration and by National Institutes of Health grant 5 T32 AM07209.

\section{REFERENCES}

1. King, C. E., and P. P. Toskes. 1979. Small intestinal bacterial overgrowth. Gastroenterology. 76:1035-1055.

2. Cameron, D. G., G. M. Watson, and L. J. Witts. 1949. The experimental production of macrocytic anemia by operations on the intestinal tract. Blood. 4:803-815.

3. Donaldson, R. M., Jr. 1965. Studies on the pathogenesis of steatorrhea in the blind loop syndrome. J. Clin. Invest. 44:1815-1825.

4. Donaldson, R. M., Jr. 1962. Malabsorption of $\mathrm{Co}^{60}$-labeled cyanocobalamine in rats with intestinal diverticula. I. Evaluation of possible mechanisms. Gastroenterology. 43:271-281

5. Giannella, R. A., W. R. Rout, and P. P. Toskes. 1974 Jejunal brush border injury and impaired sugar and amino acid uptake in the blind loop syndrome. Gastroenterology. 67:965-974.

6. Toskes, P. P., R. A. Giannella, H. R. Jervis, W. R. Rout, and $A$. Takeuchi. 1975. Small intestinal mucosal injury in the experimental blind loop syndrome. Gastroenterology. 68:1193-1203.

7. Greenlee, H. B., S. M. Gelbart, A. J. DeOrio, D. S. Francescatti, J. Paez, and G. F. Reinhardt. 1977. The influence of gastric surgery on the intestinal flora. Am. J. Clin. Nutr. 30:1826-1833.

8. Browning, G. G., K. A. Buchan, and C. Mackay. 1974. The effect of vagotomy and drainage on the small bowel flora. Gut. 15:139-142

9. Salen, G., F. Goldstein, and C. W. Wirts. 1966. Malabsorption in intestinal scleroderma. Relation to bacterial flora and treatment with antibiotics. Ann. Intern. Med. 64:834-841.

10. Goldstein F., W. C. Wirts, and O. D. Kowlessar. 1970. Diabetic diarrhea and steatorrhea. Microbiologic and clinical observations. Ann. Intern. Med. 72:215-218.

11. Pearson, A. J., A. Brzechwa-Ajdukiewicz, and C. F. 
McCarthy. 1969. Intestinal pseudo-obstruction with bacterial overgrowth in the small intestine. Am. J. Dig. Dis. 14:200-205.

12. Vantrappen, G., J. Janssens, J. Hellmans, and Y. Choos. 1977. The interdigestive motor complex of normal subjects and patients with bacterial overgrowth of the small intestine. J. Clin. Invest. 59:1158-1166.

13. Szurszewski, J. H. 1969. A migrating electric complex of the canine small intestine. Am. J. Physiol. 217:17571763.

14. Code, C. F., J. F. Schlegel. 1974. The gastro-intestinal interdigestive housekeeper: motor correlates of the interdigestive myoelectric complex of the dog. In Proceedings of the Fourth International Symposium on Gastrointestinal Motility. E. E. Daniel, editor. Mitchell Press, Ltd., Vancouver, Canada. 631-634.

15. Mathias, J. R., G. M. Carlson, D. J. DiMarino, G. Bertiger, H. E. Morton, and S. Cohen. 1976. Intestinal myoelectric activity in response to live Vibrio cholerae and cholera enterotoxin. J. Clin. Invest. 58:91-96.

16. Burns, T. W., J. R. Mathias, G. M. Carlson, J. L. Martin, and R. P. Shields. 1978. Effect of toxigenic Escherichia coli on myoelectric activity of small intestine. Am. J. Physiol. 235:E311-E315.

17. Burns, T. W., J. R. Mathias, J. L. Martin, G. M. Carlson, and $R$. P. Shields. 1980. Alteration of myoelectric activity of small intestine by invasive Escherichia coli. Am. J. Physiol. 238:G57-G62.
18. Mathias, J. R., G. M. Carlson, J. L. Martin, R. P. Shields, and S. Formal. 1980. Shigella dysenteriae I enterotoxin: proposed role in the pathogenesis of shigellosis. Am. J. Physiol. 239:G382-G386.

19. Justus, P. G., J. R. Mathias, J. L. Martin, G. M. Carlson, R. P. Shields, and S. Formal. 1981. Myoelectric activity in the small intestine in response to Clostridium perfingens A enterotoxin: correlation with histologic findings in an in vivo rabbit model. Gastroenterology. 80:902906.

20. Welkos, S. L., P. P. Toskes, and H. Baer. 1981. The importance of anaerobic bacteria in the cobalamin malabsorption of the experimental blind loop syndrome. Gastroenterology. 80:313-320.

21. Snedecor, G. W., and W. E. Cochran. 1967. Statistical Methods. Iowa State University Press, Ames, IA. 5th edition.

22. Toskes, P. P., C. E. King, J. C. Spivey, and E. Lorenz. 1978. Xylose catabolism in the experimental blind loop syndrome. Gastroenterology. 74:691-697.

23. Mathias, J. R., J. L. Martin, T. W. Burns, G. M. Carlson, and R. P. Shields. 1978. Ricinoleic acid effect on the electrical activity of the small intestine in rabbits. $J$. Clin. Invest. 61:640-644.

24. Summers, R. W., A. Dhand, L. Kuel, and D. L. Wingate. 1980. Electromyographic patterns in acute intestinal obstruction. Dig. Dis. Sci. 25:A19. (Abstr.) 